\title{
Os Sentidos e os Significados Produzidos pela Escola em Relação à Família Homoparental: Um Estudo de Caso
}

\author{
Vandernúbia Gomes Cadete ${ }^{*, a}$ Sandra Patrícia Ataíde Ferreira ${ }^{* *, b}, \&$ \\ Dayse Bivar da Silva***, \\ ${ }^{\mathrm{a}}$ Grupo Educacional Uninter, Parnamirim, Brasil, ${ }^{\mathrm{b}}$ Universidade Federal de Pernambuco, Recife, Brasil \\ $\&{ }^{c}$ Faculdade Joaquim Nabuco, Recife, Brasil
}

\begin{abstract}
RESUMO
A família tem, nas últimas décadas, sofrido significativas mudanças, que têm acarretado a formação de novas configurações familiares. Buscou-se investigar, quais os sentidos e significados produzidos pelos atores da escola em relação à família homoparental. Realizaram-se entrevistas livres com dezesseis representantes dos vários segmentos de uma escola pública, de Recife-PE. Realizou-se uma análise, a partir de três núcleos de significação, a saber: (a) consanguinidade ou cuidado?; (b) "A família estrutura é pai, mãe e filho no contexto normal"; (c) novas configurações familiares: isso não tem a ver com a escola. Identificou-se que o conceito de família está atrelado à configuração nuclear e que a homoparentalidade não é, na maioria das vezes, pensada como família e nem discutida nesse espaço educativo.
\end{abstract}

Palavras-chave: homoparentalidade; família; sentidos; significados; escola.

\section{ABSTRACT \\ The Senses And Meanings Produced by The School on The Homoparental Family: A Case Study}

The family has, in recent decades, undergone significant changes, which has entailed the formation of new family configurations. We tried to investigate what the senses and meanings are produced by the actors of schools in relation to homoparental family. We had free interviews with sixteen representatives of various segments of a public school of Recife-PE. An analysis was performed from three areas of significance, namely: 1) consanguinity or care?; 2) "The family structure is father, mother and child in the normal context"; 3) new family configurations: this has nothing to do with school. In general, we identified that the concept of family is tied to the nuclear family configuration and that homoparenthood is not, in most cases, either thought as family or discussed in the educational settings.

Keywords: homoparenthood; family; senses; meanings; school.

No cenário atual, a organização familiar tem sofrido transformações significativas no que se refere ao modelo familiar tradicional (família nuclear), devido a alguns fatores, a saber: inserção da mulher no mercado de trabalho, baixa taxa de fecundidade, declínio da instituição do casamento, entre outros. Essas mudanças sociais, culturais e também econômicas têm favorecido a formação de novos arranjos familiares, que se distanciam cada vez mais do modelo idealizado de família nuclear, apesar deste ainda prevalecer na sociedade contemporânea.

Na concepção de Shaffer (2005), a instituição familiar é entendida como sistema social, ou seja, como uma "rede complexa de relacionamentos, interações e padrões de influência, que caracterizam uma família

\footnotetext{
Endereço para correspondência: Vandernúbia Gomes Cadete - cadetevg@ gmail.com.

** Endereço para correspondência: Sandra Patrícia Ataíde Ferreira - tandaa@terra.com.br.

**** Endereço para correspondência: Dayse Bivar da Silva - daysebivar@hotmail.com.
} 
com mais de três membros" (Shaffer, 2005, p. 537). Não obstante essa concepção seja recente, ela ainda parece limitada, já que exclui o casal sem filhos da definição sobre este sistema social que é a família. Por outro lado, Althoff et al. (2001, citado por Salomé, Espósito \& Moraes, 2007) amplia essa concepção, trazendo uma definição mais flexível e possível de considerar a pluralidade; já que, para ele, a "família é uma unidade social bastante complexa e a diversidade dos aspectos que a envolvem faz reconhecer que pouco se sabe de sua realidade, especialmente, porque cada uma tende a criar o seu próprio ambiente" (Salomé, Espósito \& Moraes, 2007, p. 2).

Assim, o que se percebe hoje são diversas variações de família: adotivas; recompostas; concubinárias; temporárias; de produções independentes; biparentais; monoparentais, formadas por apenas um "pai" ou "mãe" e seus filhos; simultâneas, caracterizada pelo recasamento e pela coabitação de filhos advindos dos casamentos anteriores e por novos nascimentos (Shaffer, 2005); e, entre outras, a homoparental, que é aquela formada por duas pessoas do mesmo sexo, com filhos naturais ou adotivos, que é a composição familiar foco da presente pesquisa.

Acredita-se, portanto, que investigar a configuração familiar homoparental e como ela tem sido pensada, hoje, pela escola, torna-se relevante, à medida que poderá proporcionar à escola uma reflexão acerca da formação familiar entre pessoas do mesmo sexo e de sua função, diante dessa nova realidade social. No entanto, observa-se que os estudos realizados sobre as relações homoparentais estão voltados ou para a investigação da exclusão e identificação dos preconceitos sofridos pelos homossexuais no ambiente escolar (Andrade \& Silva, 2005) ou para a discussão da construção social da conjugalidade homossexual, no que tange à legalidade da união entre indivíduos do mesmo sexo (Mello, 2005), havendo, portanto, o interesse de se investigar e compreender os significados e sentidos produzidos por tal instituição, em relação à família homoparental, sendo este o objetivo do presente artigo.

\section{Família e escola: Compreendendo os sentidos e significados}

As novas configurações familiares na contemporaneidade têm sido alvo de discussões e questionamentos, sobretudo a família homoparental. Dentre essas questões, podemos ressaltar a ideia de que crianças criadas por pais homossexuais teriam maiores chances de se tornarem, também, homossexuais. Esta parece ser uma das principais preocupações por parte daqueles que não aceitam esse novo arranjo familiar. Contudo, algumas pesquisas (Ceccarelli, 2007a; Moz, 2006) mostram que não há evidências que comprovem que a orientação sexual dos pais influencie diretamente a dos filhos ou que prejudique o seu desenvolvimento. Neste cenário, a escola, como segunda instituição educativa, mostra-se intrinsecamente envolvida, uma vez que participa ativamente do processo de formação do sujeito nos seus aspectos cognitivo, afetivo e social, além de ser uma das responsáveis por promover e disseminar valores vivenciados culturalmente. Esses valores são construídos e reconstruídos, a partir da relação com o outro, na troca de saberes e nas construções de sentidos e significados produzidos por esses atores nesse espaço privilegiado que é a escola. Segundo Vieira e Penin (2004), a cultura exerce forte influência no indivíduo, bem como na sociedade em geral:

[...] a influência da cultura geral sobre as pessoas e as instituições não se dá de maneira determinística, de cima para baixo, mas de forma interativa, com uma via de mão dupla. Na vivência diária de uma instituição (escola, igreja, associação) e de um lugar (cidade, vila, bairro), as pessoas e os grupos que aí se formam vão também produzindo novos modos de vida humana e, assim, recriam a cultura geral. (Vieira \& Penin, 2004, p. 38)

Numa perspectiva sócio-histórica, o desenvolvimento humano decorre de trocas recíprocas que se estabelecem durante toda a vida entre sujeito e meio, em que cada aspecto exerce "forte" influência sobre o outro. Nesse sentido, Oliveira (2005, p. 126) afirma: "...ao construir seu meio, atribuindo-lhe, a cada momento, determinado significado, a criança é por ele construída; adota formas culturais de ação que transformam sua maneira de expressar-se, pensar, agir e sentir".

Trazendo essa discussão para o âmbito escolar, a Lei de Diretrizes e Bases da Educação Nacional, LDB, (Lei n. 9.394, 1996) e a Constituição Federal (1988) atribuem à escola a função de promover o pleno desenvolvimento do educando, preparando-o para a cidadania. Nesse sentido, a organização dessa instituição educativa deve ser flexível, de modo que atenda às peculiaridades regionais e locais, as diferentes clientelas e às necessidades do processo de aprendiza- 
gem. Portanto, espera-se que a escola, composta por seus diversos atores, revestida dessa função social integradora e carregada de sentidos e significados, possa contribuir para evitar que discursos excludentes e preconceituosos venham a ser difundidos e reproduzidos, uma vez que esta instituição influencia diretamente na concepção e produção destes.

Quanto à construção dos sentidos, Aguiar e Ozella (2006, p. 5) dizem que o sentido "...coloca-se em um plano que se aproxima mais da subjetividade, que, com mais precisão, expressa o sujeito, a unidade de todos os processos cognitivos, afetivos e biológicos". Já os significados atribuídos às palavras são formações dinâmicas de caráter generalizante; embora sejam mais estáveis, "dicionarizados", eles também se transformam no movimento histórico: “...os significados são construídos, ao longo da história dos grupos humanos, com base nas relações dos homens com o mundo físico e social em que vivem, eles estão em constante transformação" (Oliveira, 1997, p. 48).

Para Vygotsky (1993), o sentido de uma palavra é construído social e historicamente, a partir das experiências com o mundo.

O sentido de uma palavra é a soma de todos os eventos psicológicos que a palavra desperta em nossa consciência. É um todo complexo, fluído e dinâmico, que tem várias zonas de estabilidade desigual. O significado é apenas uma das zonas do sentido, o mais estável e preciso... O significado permanece estável, ao longo de todas as alterações do sentido. (Vygotsky, 1993, p. 125)

Compartilhando da concepção vygotskiana, Oliveira (1997) atribui à palavra "sentido" uma interpretação também subjetiva, que perpassa a relação do contexto de uso da palavra e as vivências afetivas do indivíduo. Ou seja, os sentidos podem variar, de acordo com a entonação expressiva, determinada pela situação imediata e pelo contexto psicológico no qual ela está sendo enunciada. Já o significado de uma palavra está relacionado a uma generalização ou a um conceito.

À luz da teoria de Vygotsky sobre a origem do desenvolvimento das funções mentais superiores, o pensamento e a linguagem assumem uma importância significativa, quando se pensa em investigar como os sentidos e os significados são construídos socialmente. Vale ressaltar, ainda, que este é um espaço de socialização de saberes e disseminação de conceitos historicamente construídos e, por isso, torna-se relevante pensarmos sobre a origem destes processos psíquicos.
Para Vygotsky (1993, 2000), existe uma estreita ligação entre os fenômenos do pensamento e da linguagem, o que implica dizer que esses eventos mentais são indissociáveis e que a relação entre eles se modifica historicamente, assim como os significados das palavras variam de acordo com o contexto no qual está inserido e da cultura de cada grupo social. Contudo, o pensamento e a linguagem são processos que possuem raízes genéticas e trajetórias diferentes, que se cruzam por volta dos dois anos de idade da criança. A partir desse momento, o ser humano adquire um funcionamento psicológico mais sofisticado, mediado pelo sistema simbólico de linguagem. O que, antes, caracterizava um pensamento pré-verbal do desenvolvimento do pensamento e uma fase pré-intelectual do desenvolvimento da linguagem passa, então, a se caracterizar como uma fase do pensamento verbal e da linguagem intelectual, mediada através dos signos e de instrumentos (Molon, 2000).

É a partir das mediações simbólicas que se desenvolvem a linguagem e o pensamento verbal, transformando o homem biológico num ser sócio-histórico. Nesse sentido, torna-se possível pensar a função da linguagem como um instrumento de intercâmbio social, impulsionada pela necessidade de comunicação entre os indivíduos, e do pensamento generalizante, que se refere à capacidade de agrupar ou classificar os elementos do real em categorias diversas. Assim, o ser humano, provido dessa capacidade de generalização, entenderá o mundo real, organizando os seus próprios pensamentos de forma que facilite a comunicação com o outro sujeito. Nessa relação, a linguagem assume papel primordial na organização do pensamento.

Para compreendermos melhor a construção dos sentidos e significados relacionados à gênese do conceito de família, torna-se necessário pensarmos acerca da formação dos conceitos propriamente ditos. Esta formação tem início na infância e só atinge o amadurecimento durante a adolescência, pois é nesse momento em que os conceitos passam a controlar o curso das operações mentais, canalizando-as em direção a solução de um problema (Vygotsky, 1993).

No que concerne ao conceito de família, sabe-se que este se modifica ao longo do tempo, ganhando novos sentidos através das relações sociais, bem como da cultura. Vale salientar que essa construção permeia tanto o âmbito coletivo como o individual, no qual cada membro da organização familiar pode atribuir um sentido próprio a essa palavra (família). Ademais, 
a produção de sentidos, por cada membro, provavelmente se diferenciará no que se refere à concepção construída acerca de outros modelos familiares que não o seu. Sendo assim, o conceito de cada arranjo familiar passa a ser visto e "sentido" de forma mais subjetiva, o que tem relação com os valores e crenças construídos e compartilhados socialmente (significados), como é o caso da escola. Essas modificações e reestruturações que a organização familiar tem sofrido ao longo do tempo demonstram que o modelo idealizado e reproduzido culturalmente de família nuclear tem se transformado. No que se refere à homoparentalidade, esta pode ser caracterizada pela união legalizada ou não de indivíduos do mesmo sexo que ainda esperam ser reconhecidos pela sociedade como uma instituição familiar. As justificações para a não aceitação das famílias homoparentais são diversas e estão relacionadas a fatores como: anormalidade, destituição de valores morais, tendência à homossexualidade dos filhos, entre tantos outros (Ceccarelli, 2007a; Moz, 2006).

A difusão desses discursos carregados de preconceitos é disseminada em diversos espaços; dentre eles, o escolar. E, na tentativa de compreendermos essas construções sociais (sentidos/significados), cabe levantarmos alguns questionamentos no que concerne à produção destes na/pela escola: Que discursos estão fazendo parte das práticas da escola no que se refere a essa nova conjuntura familiar? Como essa instituição está ressignificando essas transformações sociais, nas relações conjugais e parentais?

\section{MÉTODO}

Foi realizada uma pesquisa qualitativa, a partir do método de estudo de caso. Para tal, foi utilizada como técnica de coleta de dados a Entrevista Livre, orientada por apenas uma pergunta-chave, que consistiu em: O que é família para você? Esta teve, como objetivo, identificar elementos que demonstrassem as concepções que os entrevistados possuem em relação à família, a função social e educativa que essa instituição exerce no desenvolvimento do indivíduo, os motivos que justificam a aceitação ou rejeição dessa configuração familiar homoparental, a existência ou não do preconceito presente no discurso em relação a esse modelo e se esses atores percebiam o surgimento dos novos arranjos familiares, entre outros questionamentos.

Participaram deste estudo, representantes dos vários segmentos de uma instituição escolar pública, localizada na zona sul de Recife-PE, a saber: cinco professores do Ensino Fundamental (três do $1^{\circ}$ ciclo $1^{\circ}, 2^{\circ}$ e $3^{\circ}$ anos - e dois do $2^{\circ}$ ciclo $-1^{\circ}$ e $2^{\circ}$ anos), cinco alunos (um de cada turma), um coordenador, diretor e vice-diretor, uma merendeira, um porteiro e um profissional dos serviços gerais, perfazendo um total de 16 participantes. Esta escola oferece três níveis e uma modalidade de ensino, Educação Infantil, Fundamental e Educação de Jovens e Adultos (EJA), e foi escolhida pela possibilidade de acesso pedagógico, administrativo e geográfico.

Diferentemente das entrevistas com os adultos, para auxiliar na compreensão das crianças participantes desse estudo, foram utilizadas imagens que representavam diferentes configurações familiares, das quais o estudante deveria apontar a que, na sua concepção, representava uma família. A partir dessa escolha, novas perguntas eram realizadas. Assim, cada entrevista foi conduzida de forma distinta, dependendo diretamente da resposta dada por cada sujeito.

As informações adquiridas por meio das entrevistas foram analisadas, através do procedimento dos núcleos de significação propostos por Aguiar e Ozella (2006). Essa proposta apresenta três etapas fundamentais: a primeira consiste em leituras (flutuantes) iniciais do material, buscando a familiarização e apropriação dos discursos dos entrevistados, ou seja, a identificação dos pré-indicadores; a segunda objetiva apontar os indicadores (relatos significativos dos sujeitos, quanto à temática abordada) por meio do processo de aglutinação, levando em conta os critérios de semelhança, complementaridade e contraposição; a última etapa da análise está voltada para a formação propriamente dita dos núcleos de significação.

\section{RESULTADOS E DISCUSSÃO}

A partir dessa proposta de análise fundamentada na psicologia sócio-histórica, buscou-se compreender e analisar os sentidos e significados produzidos pela escola, no que concerne à família e, mais especificamente, à família homoparental. Esta abordagem sócio-histórica está sustentada no pensamento vygotskyano e busca favorecer o avanço do empírico para o interpretativo (da fala para o sentido), procurando compreender os sujeitos na sua totalidade (modos de agir, sentir e pensar), partindo da relação que há entre a fala interior, exterior e pensamento (Vygotsky, 1993). Esse método de análise permitiu ultrapassar a simples 
descrição de dados, detectando, desta forma, a gênese de alguns fatos ou fenômenos existentes no espaço escolar sobre essa temática. Desta forma, foram constituídos três núcleos de significação, a saber: (a) consanguinidade ou cuidado?, (b) "A família estruturada é pai, mãe e filho, no contexto normal", (c) novas configurações familiares: isso não tem a ver com a escola.

\section{Núcleo 1: Consanguinidade ou cuidado?}

Esse núcleo se constitui, de modo geral, da concepção que a escola (professores, alunos, gestor e os demais sujeitos do universo escolar) possui em relação ao conceito de família. A diversidade de sentidos atribuídos à palavra família esteve voltada tanto para uma visão conservadora, que está pautada na união de pai, mãe e filhos (tradicional) ou de laços sanguíneos, quanto à possibilidade da formação familiar plural, em que não só a legitimidade jurídica (certidão de casamento) e o sangue definem quem a constitui, mas os laços de afeto.

No que se refere ao modelo de família tradicional, fica implícita, a ideia de que os seus membros devemse manter fixos, como demonstra o diálogo a seguir:

\section{Pesquisador - Pra você, o que é família?}

Cláudio - Família é todo o conjunto de... que integram mãe, pai e filho, né! [...] Porque, na realidade, tio, tia, primo, eles não são família.

Pesquisador - E você acha que há um modelo ideal de família?

Cláudio - [...] Assim como eu fui criado com meu pai e minha mãe, eu também quero criar meu filho com o pai dele e a mãe dele. (Cláudio, Segurança, Escola Municipal)

Nessa concepção, a família corresponde à família nuclear, constituída por pai, mãe e filho, sendo este um modelo a ser mantido. Passos (2007) acredita que essa concepção de família nuclear está pautada em um modelo de sociedade patriarcal, que privilegia a dimensão genética da filiação, em que "a família era sustentada pela lei do pai, cuja autoridade normatizava, não só os laços parentais, mas também os conjugais e os fraternos" (Passos, 2007, p. 272). Nessa mesma perspectiva de família nuclear, a consanguinidade surge como um dos critérios para definir quem são os membros da família, por exemplo, os irmãos, que estão ligados um ao outro pelos laços de sangue.
Isso exclui, como família, outras pessoas mais próximas, ligadas apenas por laços de afeto. Observamos isso, na fala a seguir:

[...] Bom, eu acho que, a princípio, são os mais próximos da gente. [...] Mas, no meu caso, que tenho uma família assim estruturada, tudo é muito próximo, minha mãe, meu pai e minhas irmãs. A princípio, né! Eu acho que são os que são do nosso sangue. Eu acho que o esposo vem em seguida. [...] Mas, se não fosse minha família, meu pai, minha mãe, minhas irmãs, eu acho que eu não sei como eu estaria [...]. (Cleide, Coordenadora, Escola Municipal)

Cleide se refere à família como as pessoas mais próximas, que são seus pais e suas irmãs. Em seguida, ela considera o marido como se fosse sua nova família. Sendo esta formação legitimada pelos laços do matrimônio.

O outro sentido que emerge da fala dos entrevistados, a partir do questionamento do que seria família, está relacionado à aceitação da pluralidade de formação parental. Isso porque, na opinião dos sujeitos, as mudanças pelas quais a sociedade vem passando têm influenciado diretamente nas formas de organização da família. Nessa direção, Pratta e Santos (2007, p. 250) discorrem que "as análises das modificações sofridas pela família brasileira, considerando-se estes últimos anos, principalmente a década de 90, apontam para a emergência de novos arranjos familiares", sendo marcados por novas concepções de vida em conjunto. A fala a seguir exemplifica essa concepção:

Eu acho que a família é a convivência, né. Uma boa convivência. [...] Eu acho que família são aqueles que estão ao seu redor, que às vezes não são nem parentes, mas tem tanta consideração por aquela pessoa que se torna família sua, né! Eu acho que seja assim. (Nancy, Serviços Gerais, Escola Municipal)

O discurso de Nancy nos remete a uma ideia de família diferente da tradicional, uma vez que ela traz a "convivência" como sinônimo de "família". Esta, necessariamente, pode não estar relacionada aos laços sanguíneos, mas às pessoas mais próximas, aquelas que você pode contar, independente de conviverem ou não, em um mesmo espaço. Surge, então, a partir de sua fala, o sentido da "consideração", que vai além da relação mantida a partir dos laços de sangue e que, pelo contrário, fundamenta-se no contato estabelecido pelas/entre as pessoas que fazem parte do grupo familiar. 
Segundo Pratta e Santos (2007, p. 250), uma das funções da família é "garantir a sobrevivência da espécie humana, fornecendo os cuidados necessários para que o bebê humano possa se desenvolver adequadamente", o que, aliás, pode ser evidenciado na fala de Sílvia:

[...] É preciso que a família ame e cuide dos seus. Se isso acontecer, não importa se é formada por mãe, pai e filho, pode ser qualquer um. (Sílvia, Merendeira, Escola Municipal)

Compartilhando de uma ideia de conjuntura familiar como união de pessoas mais próximas com/sem laços sanguíneos, alguns participantes consideram, além de outras configurações familiares, a homoparentalidade como "família". Isso pode ser visto no discurso a seguir:

[a família homoafetiva] Eu acredito que seja família, sim. Porque eu não consigo imaginar uma família como sendo só pai, mãe e filho, não. [...] Mas eu acho normal um casal de homossexual. Pra mim, se eles estão unidos ali com essa função, com esse objetivo de construir uma família mesmo, de seguir um ideal, uma coisa assim. Então, eles são família [...]. (Joana, Auxiliar de Coordenação, Escola Municipal)

Analisando o discurso de Joana, observamos que não há preconceito, quanto ao reconhecimento da união de pessoas do mesmo sexo como família, pois, o que parece ser mais importante para ela é o cuidado que os "pais", independente de quem esteja exercendo essas funções, devem ter com os filhos, contanto que estes compartilhem de um mesmo objetivo: formar uma família. Dentro dessa perspectiva, os papéis parentais são mais flexíveis. Eiguer et al. (2004, citado por Passos, 2007) afirmam que "Ninguém é pai. O pai é feito pelos outros. É família que o faz. É claro que essa mesma lógica deve ser transportada para as demais funções: materna, fraterna, etc." (Passos, 2007, p. 277).

Essa formação de família homoparental se contrapõe ao modelo tradicional patriarcal, pois suas leis internas e funções são mais plásticas, "onde os cidadãos criam e recriam mais livremente suas experiências afetivas" (Passos, 2005, p. 33). Analisando o discurso abaixo, podemos ver surgir outros sentidos que se contrapõem à ideia de hierarquia, papéis fixos e da consanguinidade, na estrutura familiar.
Eu acho assim, que tem mãe, por aí, e pais que são diferentes e não tratam os filhos tão bem como essas pessoas do mesmo sexo. [...] Se eles estão fazendo o papel do pai $e$ da mãe, por que ignorar? Tudo bem que criar com o pai e a mãe é ideal, mas se tão cuidando, eu não vejo por que não. Então, o que vale para criança, é isso. (Nancy, Serviços Gerais, Escola Municipal)

Para Nancy, não importa a configuração familiar na qual a criança está inserida, mas a forma com que os pais "tratam" e cuidam dos seus filhos, ou seja, o mais importante é que a família garanta as condições básicas para o desenvolvimento da criança. Segundo Passos (2007), a criança necessita, para sobreviver, pelo menos, de quatro premissas: (a) ser recebida e acolhida com os cuidados necessários a sua subsistência física e psíquica, (b) ser inserida na cadeia de filiação e, para tanto, deve ser reconhecida pela mãe como filho, (c) da inserção do pai na relação mãe e filho, para o estabelecimento de uma triangulação necessária para a construção de um mundo simbólico, para a criança e (d) do conhecimento da própria origem, seja ela qual for.

Embora a maioria dos participantes reconheça a existência de uma variedade de configurações familiares na sociedade contemporânea, não confere esse status à configuração homoparental. Vale salientar, ainda, que, na concepção de algumas crianças, essa formação familiar parece inconcebível, uma vez que isso causa estranheza e a ideia de "errado" ou algo não natural. O diálogo a seguir, com o aluno Will, $3^{\circ}$ Ano do $1^{\circ}$ Ciclo, ilustra claramente esse ponto de vista:

Pesquisador - Então, essa não pode ser família? [mostrando, para a criança, uma imagem de família homoparental]

Aluno - Não.

Pesquisador - Você nunca viu uma família assim?

Aluno - Não.

Pesquisador - E se você visse, o que é que você iria achar?

Aluno - Ruim.

Pesquisador - Ruim? Por que é ruim ter uma família assim?

Aluno - Porque é errado.

Pesquisador - Errado por quê? O que tem de errado com uma família assim? 
Aluno - Porque tem duas mulheres.

Pesquisador - Não pode, não, ter duas mulheres?

Aluno - Pode não.

Pesquisador - E pode ter como?

Aluno - Um homem e uma mulher.

Podemos observar, na fala do aluno, que a não aceitação da união entre pessoas do mesmo sexo parece estar pautada ao conceito de família biparental, em que se torna imprescindível a presença do homem e da mulher, para que haja a formação da família/casal.

\section{Núcleo 2: A família estrutura é pai, mãe e filho, no contexto normal}

Esse núcleo se formou a partir dos discursos de alguns sujeitos da escola, nos quais se identificou que a família, dita como "estruturada", estava associada ao modelo de família nuclear. Essa ideia fica clara na fala de Cléa, professora, $2^{\circ}$ ano do $2^{\circ}$ ciclo:

A família estruturada é pai, é mãe e filhos, no contexto normal, né! Mas no contexto que estamos vivendo é... tá tudo distorcido, né! Mas a família [...] A partir do momento que se abre exceção pro contexto de família ser qualquer outro contexto a não ser esse, a sociedade começou a desandar. Nessa desorganização, é difícil ser equilibrado. Eu acho que o principal seja essa parte da família desestruturada, não mais o contexto de pai, mãe e filhos. (Cléa, Professora, $2^{\circ}$ ano do $2^{\circ}$ ciclo, Escola Municipal)

No discurso da professora Cléa, podemos perceber que as novas configurações familiares representam uma ameaça à sociedade, uma vez que o que foge ao padrão "pai, mãe e filhos" é sinônimo de desestruturação social e de desequilíbrio pessoal. Logo, poderíamos inferir que existe uma base comum, que mantém a estrutura social e familiar organizada: a configuração pai, mãe e filho.

Nesse sentido, a cultura exerce forte influência no modo de agir e pensar dos sujeitos, impondo um "modelo" de vida em que tudo é tomado como estando preestabelecido, em especial, o papel social que cabe a cada sujeito. Contudo, no contexto atual - de mudanças socioeconômicas, das novas tecnologias, etc. -, a redefinição dos papéis sociais se apresenta como uma consequência dessas transformações pelas quais a sociedade vem passando, afetando, deste modo, as formas de organização parental. Vale salientar, também, que, para Ceccarelli (2007b, p. 315), "as referências simbólicas que definem o modelo familiar são passíveis de remanejamento e reorganização".

Podemos apreender, ainda, que, na concepção de Cléa, o indivíduo não consegue se equilibrar, vivendo em um contexto familiar com outro tipo de organização que não o tradicional. Sendo assim, podemos inferir, a partir dessa discussão, que a organização familiar tradicional parece ser o único modelo capaz de promover o desenvolvimento saudável do sujeito. O único capaz de transmitir valores e princípios que regem a estrutura social contemporânea (Ceccarelli, 2007a). No entanto, como dizem Pratta e Santos (2007, p. 248), “[...] os diferentes tipos de composições familiares são determinados por um conjunto significativo de variáveis ambientais, sociais, econômicas, culturais, políticas, religiosas e históricas." Por isso, não se pode definir configuração familiar, sem levar em consideração o momento histórico que a sociedade vem passando, nem tampouco as diferentes culturais.

Vale ressaltar que essas transformações na estrutura familiar também exercem forte influência nas relações sociais, tanto no âmbito privado quanto no coletivo, como, por exemplo, o cuidado dos filhos que era exclusivo da mãe e que passou a ser também de responsabilidade do pai ou de outros membros da família, alterando a concepção dos sujeitos, no que se refere ao modo de conceber as novas configurações familiares.

No que se refere à formação da família homoparental, esteve presente, ainda, em alguns discursos, a ideia de que filhos de pais homossexuais vão ter seu desenvolvimento prejudicado quanto ao desvio de comportamento. Para a professora Vânia, uma configuração que foge do modelo de pai e mãe é complicada:

[...] Eu acho que prejudica e muito. Não é uma questão de preconceito, não. Cada um é o que é, cada um vai ser o que quiser ser, mas, na realidade, é uma coisa que não é normal [...]. A gente já tem problema com pai e mãe e com padrasto e madrasta, imagina uma situação dessa [...]. (Vânia, Professora, $3^{\circ}$ ano do $1^{\circ}$ ciclo, Escola Municipal)

Vânia, pautada na ideia de formação nuclear - pai, mãe e filhos - atribui a essa configuração o critério de "normalidade", ao mesmo tempo em que expressa a ideia de que a configuração familiar homoparental pode trazer problemas mais graves para o filho que 
compõe essa família, inclusive na/para a escola, do que aqueles vivenciados pelos filhos de famílias biparentais.

Outro sentido, presente nos discursos dos entrevistados, está relacionado à preocupação quanto à futura manifestação sexual da criança. O diálogo, a seguir, evidencia a ideia de que a família homoparental tem implicações negativas, na constituição da "identidade" sexual de seus filhos:

Pesquisador - Você acredita que a criança criada por pais homossexuais vai ter seu desenvolvimento prejudicado?

Vânia - Vai. Na minha forma de ver, vai.

Pesquisador - Por quê?

Vânia - Porque vai. Ele vai crescer vendo aquela situação, é aquilo que ele conhece: pai e mãe dois homens, pai e mãe duas mulheres. Ele vai conhecer aquela estrutura ali e ele vai crescer achando que aquilo ali é uma coisa que é muito normal, dentro da sociedade, e a tendência é seguir aquilo ali [...]. (Vânia, Professora, $3^{\circ}$ ano do $1^{\circ}$ ciclo, Escola Municipal)

Podemos observar, no recorte de fala acima, a crença de que o desenvolvimento da criança de pais homossexuais seria prejudicado, uma vez que o papel de pai e mãe não fica claramente definido na "mente" da criança, quando comparado com o modelo "ideal" de família tradicional. Nessa direção, Passos (2007) afirma que boa parte dos argumentos contra a homoparentalidade está relacionada à ausência de diferenciação sexual entre os pais, ou seja, à ideia de que "os filhos crescem sem referências ou referências distorcidas, o que acarretaria problemas de disfunções de natureza sexual" (Passos, 2007, p. 274).

Os entrevistados, ainda, apontam o preconceito social como um aspecto que influencia negativamente o desenvolvimento da criança (filhos de pais homossexuais). Isso ocorre, na maioria das vezes, devido ao não reconhecimento e respeito à cultura do outro, suas crenças, seus valores, religião, etc. Isto é o que fica explícito, no discurso do Segurança da escola:

Não em relação aos pais serem homossexuais, mas envolve a sociedade lá fora, porque vai prejudicar a vida da criança. [...] Na escola [...] vão começar a perturbar a cabeça dela e ela vai chegar até não querer vim mais pra escola, como já aconteceu em relação à criança que tem o HIV, né! Descriminar desestimula a criança a ir pra escola. (Cláudio, Segurança, Escola Municipal)
Compartilhando dessa mesma ideia, a Coordenadora diz:

[...] eu acho que o mais difícil para essa criança é que ela vai receber na vida dela já muito preconceito. Querendo ou não, onde ela estiver, na convivência e na sociedade, infelizmente, ela se depara com muito preconceito. (Cleide, Coordenadora, Escola Municipal)

Percebemos que, tanto no discurso de Cláudio, como no de Cleide, há uma preocupação com a criança, no que concerne à discriminação por parte de outros sujeitos, advindos de uma configuração familiar considerada como "normal". Nessa perspectiva, Passos (2007, p. 280) indica que este "talvez seja o maior impasse vivido por essas crianças". E, a partir de alguns depoimentos, a autora demonstra que os filhos de pais homossexuais não teriam problemas em aceitar a conjugalidade dos pais, contanto que esses não fossem vistos como estranhos e produto de ilegalidade.

Um outro sentido, presente nos discursos dos sujeitos em relação à organização familiar, refere-se à religiosidade, que toma como modelo de família idealizado o padrão divino "pai, mãe e filho". A fala, a seguir, explicita esse pensamento:

Família é a célula mater da sociedade. Família é o primeiro projeto de Deus pro homem. [...] Se você for observar... a criação de Deus [...] então, hoje nós temos a família completamente fora desses padrões. Muitas famílias. [...] A gente vê casos hoje de homossexuais masculinos, não é? [...] Eu reconheço que a coisa de pai e de mãe. Do ponto de vista psicológico, a função de pai é uma e a função de mãe é outra e, do ponto de vista do homem, ela é independente do sexo, tá certo? Só que, para mim, eu acho que isso fere esse padrão do que deveria ser família e eu acho que é por isso que a gente tem tanta desestrutura. (Iraci, Gestora, Escola Municipal)

Podemos observar, na narrativa da gestora, tanto o discurso de conteúdo psicológico quanto religioso, este se sobrepondo ao primeiro. Há, portanto, a presença de dois grandes referenciais, para justificar sua posição quanto às funções desempenhadas pelo pai e pela mãe, na organização familiar. Enquanto um aponta que "mais do que os signos da sexualidade, são os enunciados simbólicos que diferenciam as posições assumidas pelo casal parental no contexto de uma filiação" (Passos, 2007, p. 279), o outro encontra-se baseado no "imaginário judaicocristão, determinando nosso sistema de valores ético-morais" (Ceccarelli, 2007b, p. 314). 
Para a gestora, a desestrutura familiar está associada à falta de crença em Deus, ou seja, à falta de obediência aos princípios religiosos da conjugalidade - "até que a morte os separe". Obedecer a esses princípios é, pois, manter a formação familiar em uma situação estável e segura para seus membros, em que ficam claramente definidas as funções que cada um desempenha. Portanto, o "homem", ao se afastar desses princípios, rompe a aliança de fidelidade a Deus e ao matrimonial, comprometendo a base que sustentava essa união e modificando, assim, a estrutura familiar autorizada pela Igreja e, consequentemente, pela força divina (pai, mãe e filhos).

Compartilhando dessa mesma ideia de configuração familiar relacionada à religiosidade, Érica diz:

[...] Família, pra mim, é a base de tudo, por isso que a nossa sociedade está desestruturada, as escolas estão todas com problemas, os alunos quase todos não têm família. Eu tô vendo várias famílias desestruturadas, sem amor, sem uma religião [...]. (Érica, Professora, Escola Municipal)

Na fala de Érica - "as escolas estão todas com problemas, os alunos quase todos não têm família" - fica implícita a ideia de que a configuração familiar tradicional seria a única a evitar problemas para a escola, como, por exemplo, as questões relacionadas à (in)disciplina e ao respeito ao próximo.

A professora, ainda, acredita que tanto a sociedade quanto as famílias estão desestruturadas, associando "família estruturada" à "família tradicional". Esta, por sua vez, fundamentada em regras de convivência baseadas no autoritarismo e centralidade da figura do pai, sendo os filhos considerados, em geral, como indivíduos passivos e sem autonomia. Desvelando, assim, a concepção de criança que a desconsidera como um ser potencial, em que a construção da subjetivação e da especificidade do sujeito é tomada como um processo importante, para a construção da sua identidade. Diferentemente da família homoafetiva que, segundo Passos (2005, p. 37), é "marcada pela inexistência de hierarquia e por uma circulação permanente das lideranças no grupo", embora também se saiba que, hoje, a família biparental também passa por mudanças nos papeis que seus membros desempenham, em decorrência das demandas socioculturais.

Enfim, percebemos, de modo geral, nas narrativas analisadas, que a família estruturada, (pai, mãe e fi- lho), na visão dos entrevistados, está atrelada, principalmente, a questões morais, isto é, à religião e à ética. Desse modo, uma formação familiar diferente desta, como, por exemplo, a homoparental, é vista de forma preconceituosa e como determinante da manifestação sexual dos filhos, ou seja, filhos de pais homossexuais serão também, homossexuais.

\section{Núcleo 3: Novas configurações familiares: Isso não tem a ver com a escola}

Esse núcleo está relacionado às concepções que os diferentes sujeitos possuem, no que diz respeito ao modo como a escola tem pensado sobre a formação das novas configurações familiares, dentre elas, a homoparental. Os entrevistados, em sua maioria, alegam não haver reflexões acerca dessa realidade que se configura na escola. Contudo, outros participantes ressaltaram a relevância de suscitar discussões e debates a esse respeito, devido ao fato dos estudantes advirem de diferentes configurações familiares e da necessidade de se conhecer o contexto no qual o estudante está inserido.

Verificou-se, entre outros aspectos, que a configuração homoparental aparece, em alguns discursos, relacionada ao sentido de "respeito". O recorte de fala abaixo evidencia essa ideia:

Eu tenho caso... e agora, os meninos já não são mais alunos nossos, mas eu tinha dois irmãos que eram criados por duas mulheres e eles sempre foram tratados de uma forma igual, como qualquer outra criança, na escola. Até porque a minha opinião não vai poder prevalecer sobre a condução do trabalho na escola. (Iraci, Gestora, Escola Municipal)

Na concepção da entrevistada, a escola precisa "tratar" da mesma forma todos os alunos, independente das suas próprias concepções, uma vez que ela se constitui num espaço educativo que lida com diversidade de sujeitos, dotados de especificidades. Por isso, a escola precisa garantir a igualdade dos direitos a todos (alunos) e respeitar as diferenças individuais e culturais. Contudo, diante do que foi analisado, essa ideia de igualdade expressa uma contradição, já que a formação familiar homoparental ainda não é concebida como família, dentro do espaço escolar nem fora dele.

No que se refere ao modo como a escola tem pensado sobre as mudanças pelas quais a família vem passando na sociedade contemporânea, sobretudo, os 
novos arranjos familiares, identificamos um pensamento comum a grande maioria dos participantes. Este pensamento pode ser expresso na seguinte fala:

[...] na verdade, na escola ninguém tem falado sobre isso. A gente nunca se reuniu para falar sobre isso, pra debater sobre isso, mas a gente percebe, assim, nos alunos da gente, que muitas famílias são nos novos padrões. Exatamente, como, por exemplo: uma mãe que toma conta de tudo, uma mãe que larga o filho e vai embora e o pai apoia, com a avó paterna assume e, nesse caso, eles se separam e um dos dois assume tudo, apesar do outro lado existir. Mas, na escola ninguém fala sobre isso não, pelo menos não aqui. (Eliza, Professora, $1^{\circ}$ ano do $2^{\circ}$ ciclo, Escola Municipal)

Podemos perceber, na narrativa da professora Eliza, que, apesar dela reconhecer a existência de outros modelos de família, a homoparental não é citada, predominando, assim, o "silêncio", acerca dessa configuração. Esse silêncio pode ser interpretado como o reflexo da ilegalidade e do preconceito, que permeiam a composição familiar homoafetiva, em que a maior vítima é a criança. Logo, o não reconhecimento dessa união como família provoca um sentimento de vergonha para os sujeitos da relação homoparental que, por sua vez, preferem silenciar quanto a sua "identidade familiar". Essa legalidade é imprescindível para que a criança adquira confiança em si mesma e nos outros.

No entanto, essa realidade é percebida não só no contexto educacional como também no familiar, que se configura na clandestinidade. Segundo Passos (2005, p. 9), "é muito frequente pais ou mães homossexuais silenciarem em relação à existência do(a) parceiro(a), pois como pais celibatários são muito mais aceitos, socialmente".

Uma das entrevistadas, além de compartilhar da mesma ideia da professora Eliza (que a escola não tem refletido sobre essa realidade), acredita que esta também não é sua função.

[...] Eu acho que a escola não tem a ver, não. Eu acho que o que tem a ver são as mães, né? [...]. (Sílvia, Merendeira, Escola Municipal)

Ao se analisar esse recorte de fala, percebemos que Sílvia atribui à mãe a responsabilidade de manter a família unida a qualquer custo - "ser mãe é padecer no paraíso". Distinguindo, desta forma, as funções que cabe a cada instituição, familiar e escolar, sem considerar que ambas têm uma função em comum: “...o fato de prepararem os membros jovens para sua inserção futura na sociedade e para o desempenho de funções que possibilitem a continuidade da vida social" (Szymanski, 2003, p. 61). Portanto, é essencial que ambas as instituições estejam articuladas e adquiram conhecimento mútuo, para que atividades como "festas de pais" ou "de mães" ganhem significado para as crianças/filhos, quando seu contexto familiar for outro, diferente do tradicional. Mas, para isso, faz-se necessário que a escola não esteja pautada em concepções estereotipadas da figura masculina e feminina.

Outro sentido que surge, a partir desse enunciado, está relacionado à função social da escola. Para a professora Silvia, parece não caber a esta, a responsabilidade de trazer esse tipo de discussão, uma vez que envolve questões do âmbito familiar e precisam ser "resolvidas" nesse espaço privado. Nessa concepção, acaba se priorizando apenas uma das várias funções que a escola exerce na sociedade - a de "transmissão do conhecimento", desconsiderando-se, assim, a formação integral do sujeito, que envolve o desenvolvimento de outras dimensões (afetiva, corporal, social), do qual a escola também precisa participar.

Ocorre que, muitas vezes, a escola não acompanha as mudanças pelas quais a sociedade vem atravessando e acaba dirigindo suas ações, pautada num modelo de família tradicional, quando, na verdade, nem sempre ele coincide com a realidade das famílias contemporâneas. Sobre essa questão, Lacasa $(2004$, p. 414) afirma que "...a escola não pode esquecer o mundo familiar, os conteúdos de suas bases de conhecimento e as metas do ensino e de todas as pessoas adultas que participam no processo educacional da criança". Portanto, a escola, hoje, "além da função de socializar o saber sistematizado, a ela cabe ensinar a convivência democrática, o respeito aos direitos e deveres individuais e coletivos" (Vieira \& Penin, 2004, p. 33).

Enfim, os discursos dos entrevistados trazem, implicitamente, significados relativos à questão da legalidade/ilegalidade referente à configuração familiar homoparental, em que o silêncio predomina, no espaço escolar. Outro significado presente consiste na ideia do privado, em relação à família, em que pensar sobre as novas mudanças, no modelo de organização familiar, cabe, somente, a esta instituição, deixando a escola à parte da responsabilidade de se pensar sobre essas questões. 


\section{CONSIDERAÇÕES FINAIS}

A homoparentalidade tem sido bastante discutida na sociedade contemporânea, sendo necessário saber como a escola reflete ou ressignifica os discursos sobre essa nova configuração familiar. Assim, esta investigação objetivou apreender os sentidos e significados produzidos pelos atores de uma dada escola, acerca da homoparentalidade.

De modo geral, verificamos que grande parte dos entrevistados estava pautada no significado de família nuclear, sendo esta considerada a referência de família capaz de promover o desenvolvimento saudável da criança, o que está de acordo com os estudos de Ceccarelli (2007b), que afirma que a família dita tradicional "continua sendo o de referência nas discussões sobre família, como se fosse o único capaz de sustentar a ordem social e de produzir subjetivações sadias" (Ceccarelli, 2007b, p. 312).

Também evidenciamos, nos discursos dos sujeitos entrevistados, por um lado, o predomínio do silêncio, acerca da configuração familiar homoparental e, por outro, a ideia de que não compete à instituição escolar pensar sobre isso; desvelando-se, no dito e no não dito, a negação de sua existência.

Outros significados que emergiram dos discursos dos atores da escola estiveram relacionados à possível discriminação que crianças, filhos de pais homossexuais, sofrem ou poderão sofrer nas interações com outros indivíduos, advindos de configurações familiares ditas como "normais", bem como à ideia de uma predisposição, dessas crianças, em seguir a manifestação sexual dos seus progenitores. Como aponta Dubreuil et al. (1998, citado por Passos, 2007), a referência de apenas um dos sexos, para a criança, é um dos principais questionamentos, quando se discute a legalização da família homoparental nos tribunais: "Segundo esse raciocínio, um modelo único permite apenas a identificação a um tipo de sexualidade, podendo, em muitos casos, facilitar a orientação homossexual dos filhos e dificultar a integração dos mesmos na sociedade" (Passos, 2007, p. 274). O que, por sua vez, parece evidenciar a produção, por parte da escola investigada, de significados estáveis e generalizantes, acerca do conceito de família, os quais foram construídos ao longo da história e apreendidos por seus atores (Vygotsky, 1993).

No entanto, verificamos que novos sentidos referentes à homoparentalidade vivenciam uma relação de tensão com os significados mais estáveis, dentro do contexto escolar investigado. Assim, o cuidado aparece como um dos critérios principais para se constituir uma família unida pelos laços de afeto e não apenas a consanguinidade.

Portanto, a partir do presente estudo, novos questionamentos, passíveis de investigação, emergiram: qual o ponto de vista das crianças, filhas de pais homossexuais, sobre a sua própria configuração familiar? Quais os possíveis preconceitos e privações sofridos por elas no ambiente escolar? Pesquisar esses temas é de grande relevância para que se possa mudar atitudes, comportamentos e significados, compartilhados socialmente. Além disso, acreditamos que essas sugestões de estudos sejam passos na construção de uma sociedade mais justa e plural, onde as diversidades sejam respeitadas, não excluídas e ressignificadas.

\section{REFERÊNCIAS}

Aguiar, W. M. J., \& Ozella, Z. (2006). Núcleos de significação como instrumento para a apreensão da constituição dos sentidos. Psicologia: Ciência e Profissão, 26, 222-245. Retirado em 18 de abril de 2008, da base de dados SciELO.

Andrade, A. J., \& Silva, T. T. (2005). Representações de exclusão na educação: Onde estão os homossexuais? (Monografia de conclusão de graduação). Universidade de Brasília. Retirado em 20 de abril de 2008, de http://www.fbb.org.br/bbeducar/ pages/publico/expandir.fbb?codConteudoLog=1496

Ceccarelli, P. R. (2007a). Novas configurações familiares: Mitos e verdades. Jornal de Psicanálise, 40, 89-102. Retirado em 10 de abril de 2008, da base de dados SciELO.

Ceccarelli, P. R. (2007b). As bases imaginárias da família. Em T. Féres-Carneiro (Org.), Família e casal: Saúde, trabalho e modos de vinculação (pp. 311-320). São Paulo: Casa do Psicólogo.

Constituição da República Federativa do Brasil (1988). Texto constitucional promulgado em 5 de outubro de 1988, com as alterações adotadas pelas Emendas Constitucionais $n^{\circ} 1 / 92$ a 48/2005 e pelas Emendas Constitucionais de Revisão $n^{\circ} 1$ a 6/94. Brasília, DF: Senado Federal, Subsecretaria de Edições Técnicas, 2005.

Lacasa, P. (2004). Ambiente familiar e educação escolar: A interseção de dois cenários educacionais. Em C. Cool, A. Marchesi, \& J. Palacios (Orgs.), Desenvolvimento psicológico (pp. 403419). Porto alegre: Artmed.

Lei n. 9.394, de 20 de dezembro de 1996 (1996, 20 de dezembro). Lei de Diretrizes e Bases da Educação Nacional. Brasília, DF: Senado Federal, Subsecretaria de Edições Técnicas, 2003.

Mello, L. (2005). Outras famílias: A construção social da conjugalidade homossexual no Brasil. Cadernos Pagu, número 24, 197-225. Retirado em 10 de abril de 2008, da base de dados SciELO.

Molon, S. I. (2000). Subjetividade e constituição do sujeito em Vygotsky. Trabalho apresentado na III Conferência de Pesquisa Sociocultural, Campinas. Retirado em 21 de março de 2008, de http://www.fae.unicamp.br/br2000/indit.htm 
Moz, M. (2006). Diferenças de gênero e famílias homoparentais. Retirado em 21 de março de 2008, de http://ilgaportugal.pt/ficheiros/pdfs/MozMargarida.pdf

Oliveira, M. K. (1997). Vygotsky: Aprendizado e desenvolvimento, um processo sócio-histórico. São Paulo: Scipione.

Oliveira, Z. R. (2005). Educação infantil: Fundamentos e métodos. São Paulo: Cortez.

Passos, M. C. (2005). Homoparentalidade: Uma entre outras formas de ser família. Psicologia Clínica, 17, 31-40. Retirado em 20 de março de 2008, da base de dados SciELO.

Passos, M. C. (2007). Funções materna e paterna nas famílias homoparentais. Em T. Féres-Carneiro (Org.), Família e casal: Saúde, trabalho e modos de vinculação (pp. 269-321). São Paulo: Casa do Psicólogo.

Pratta, E. M. M., \& Santos, M. A. (2007). Família e adolescência: A influência do contexto familiar no desenvolvimento psicológico de seus membros. Psicologia em Estudo, 12, 247-256.

Salomé, G. M., Espósito, V. H. C., \& Moraes, A. L.H. (2007). O significado de família para casais homossexuais. Revista Brasileira de Enfermagem, 60, 559-563. Retirado em 20 de março de 2008, da base de dados SciELO.
Shaffer, D. R. (2005). Psicologia do desenvolvimento: Infância e adolescência. São Paulo: Pioneira Thomson.

Szymanski, H. (2003). A relação família/escola: Desafios e perspectivas. Brasília: Plano.

Vieira, S. L., \& Penin, S. T. S. (2004). Refletindo sobre a função social da escola. Em S. L. Vieira (Org.), Gestão da escola: Desafios a enfrentar (pp. 13-45). Rio de Janeiro: DP\&A.

Vygotsky, L. S. (1993). Pensamento e linguagem (J. L. Camargo, Trad.). São Paulo: Martins Fontes.

Vygotsky, L. S. (2000). A construção do pensamento e da linguagem (P. Bezerra, Trad.). São Paulo: Martins Fontes.
Recebido: 16/04/2010 Última Revisão: 07/02/2012 Aceito: 25/04/2012 